\title{
Feasibility Verification of Mountable PZT-Interface for Impedance Monitoring in Tendon-Anchorage
}

\author{
Thanh-Canh Huynh, ${ }^{1}$ Young-Hwan Park, ${ }^{2}$ Jae-Hyung Park, ${ }^{1}$ and Jeong-Tae Kim ${ }^{1}$ \\ ${ }^{1}$ Department of Ocean Engineering, Pukyong National University, 599-1 Daeyeon 3-dong, Nam-gu, Busan 608-737, Republic of Korea \\ ${ }^{2}$ Structural Engineering Division, Korea Institute of Construction Technology, Gyeonggi-do 411-472, Republic of Korea \\ Correspondence should be addressed to Jeong-Tae Kim; j0k9180@gmail.com
}

Received 5 September 2014; Accepted 27 November 2014

Academic Editor: Ting-Hua Yi

Copyright (c) 2015 Thanh-Canh Huynh et al. This is an open access article distributed under the Creative Commons Attribution License, which permits unrestricted use, distribution, and reproduction in any medium, provided the original work is properly cited.

\begin{abstract}
This study has been motivated to numerically evaluate the performance of the mountable PZT-interface for impedance monitoring in tendon-anchorage. Firstly, electromechanical impedance monitoring and feature classification methods are outlined. Secondly, a structural model of tendon-anchorage subsystem with mountable PZT-interface is designed for impedance monitoring. Finally, the feasibility of the mountable PZT-interface is numerically examined. A finite element (FE) model is designed for the lab-scaled tendon-anchorage. The FE model of the PZT-interface is tuned as its impedance signatures meet the experimental test results at the same frequency ranges and also with identical patterns. Equivalent model properties of the FE model corresponding to prestress forces inflicted on the lab-tested structure are identified from the fine-tuning practice.
\end{abstract}

\section{Introduction}

The fundamental of the impedance-based method is to utilize the electromechanical (EM) impedance of a coupled PZTstructure system to detect the change in structural characteristics at local critical region. This monitoring technique was first proposed by Liang et al. [1]. Since then, many researchers have improved the method and applied it into various damage detection problems [2-7]. Kim et al. [8, 9] applied the impedance-based method for prestress-loss monitoring in tendonanchorage connection by detecting the change in the pattern of the impedance responses at the anchorage.

Although the method has shown the excellent performance in detecting prestress-loss in tendon-anchorage, it still has several limitations for practical applications. Firstly, the effective frequency band which is sensitive to the variation of prestress force could be very significant, even above $800 \mathrm{kHz}$ [9]. In this case, a high performance impedance analyzer is needed to get signals from such a high frequency range. Therefore, it is almost impossible to adopt a wireless impedance device which has a measurable frequency range of $10 \mathrm{kHz} 100 \mathrm{kHz}[10,11]$. Secondly, the impedance frequency bands which are sensitive to prestress-loss should be predetermined before employing the impedance-based method for the damage detection job. Generally, the effective frequency range is varied dependent on target structures and usually determined by trial and error. This causes difficulty when dealing with real structures.

To overcome the abovementioned limitations, Nguyen and Kim [12] designed a fixed-type PZT-interface for monitoring prestress-loss in tendon-anchorage subsystems. The implementation of the PZT-interface was successful as sensitively indicating various prestress-losses in the tendonanchorage. Also, the sensitive frequency range to prestressloss was reduced to below $100 \mathrm{kHz}$. However, this design of PZT-interface must be installed during the construction of the tendon-anchorage connection. So it is impossible to apply it into existing cable-supported structures. Also, the presence of the aluminum PZT-interface between anchor and bearing plate may cause the loss of the bearing capacity of the connection.

To deal with these drawbacks of the fixed-type PZT-interface, a mountable PZT-interface was proposed by Huynh and Kim [13], as shown in Figure 1, for impedance monitoring of 


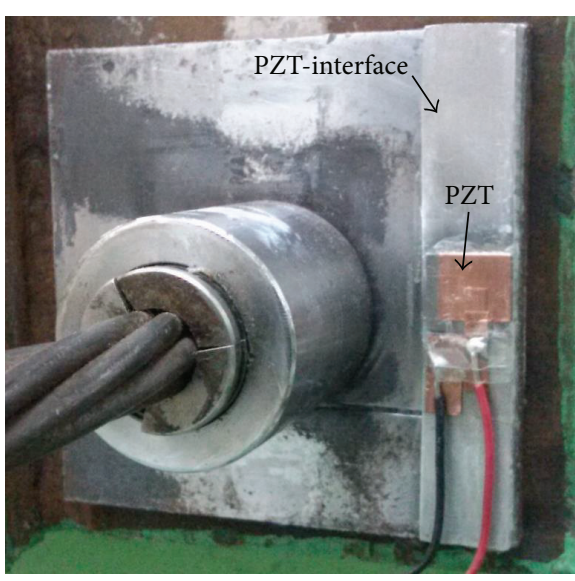

(a)

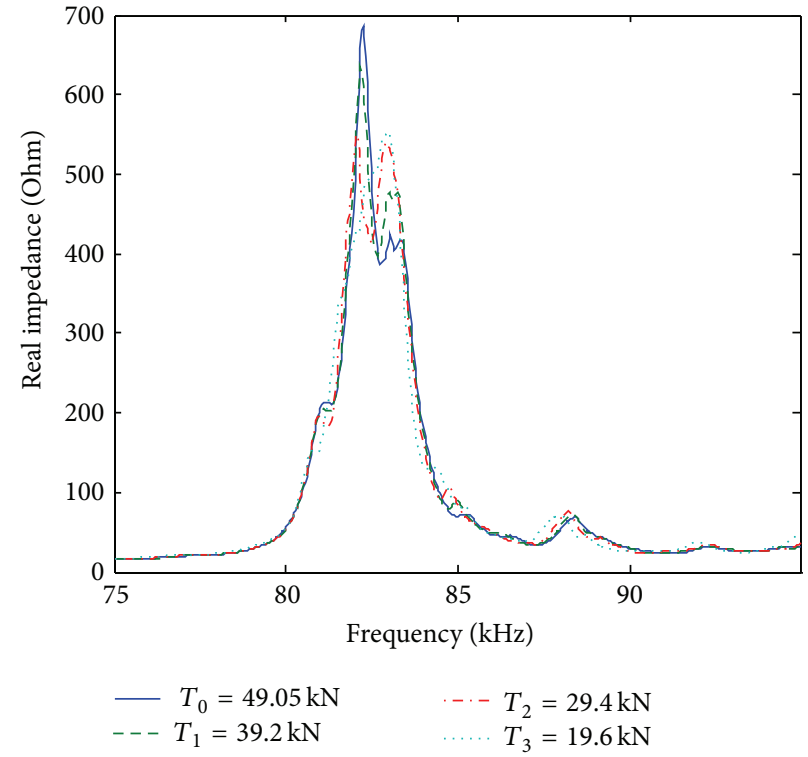

(b)

Figure 1: Prestress-loss monitoring using PZT-interface [13]: (a) mountable PZT-interface and (b) impedance signatures for prestress forces.

tension forces from existing tendon-anchorages. This interface can be easily bonded on and also detached from the anchorage surface as it is a clamped-clamped beam embedded with a PZT patch. Although the new PZT-interface was successfully tested for tension-loss monitoring from a labscaled tendon-anchorage, its feasibility should be verified by numerical simulation. Since the PZT-interface's geometry should be fitted dependent on host structures, the numerical simulation (as well as verification) is the key to the design of appropriate PZT-interfaces corresponding to the target's specifications.

In the numerical simulation of the electromechanical impedance, the coupling interaction between the PZT sensor and the host structure is an important issue. Several simplified impedance models have been proposed for describing the PZT sensor-structure interaction. Liang et al. [1] developed a 1-dof spring-mass-damper system via combining the electromechanical analysis of a PZT sensor and the structural dynamic analysis of the host structure. To consider the multidirectional effects caused by the PZT sensor's vibration, Zhou et al. [14] and Bhalla and Soh [15] introduced two-dimensional impedance models from which the planar coupled vibration was taken into account. By adopting the effective impedance concept, Zuo et al. [16] have developed a three-dimensional PZT-structure model considering the coupled vibration along the radial direction and along the thickness direction of the PZT sensor. The performance evaluation of the theoretical impedance models has been validated by experimental tests conducted on beam-like structures $[1,17]$ and thin plates $[14,15]$ with bonded PZT actuators. However, the direct application of the so-called "impedance model" is limited when dealing with host structures with complex characteristics (i.e., geometry, material properties, and boundary conditions). In such cases, appropriate modeling techniques are needed to fully capture the coupled vibration of the PZT sensor and the host structure.

This study has been motivated to numerically evaluate the performance of the mountable PZT-interface for impedance monitoring in tendon-anchorage. Firstly, electromechanical impedance monitoring and feature classification methods are outlined. Secondly, a structural model of the anchorage's components is designed from the force equilibrium state. In the model, the tension force is represented by interfacial structural parameters of the tendon-anchorage connection. A mountable PZT-interface is designed for tension-loss monitoring from postinstallation into existing anchorages. Finally, the feasibility of the mountable PZT-interface is numerically examined. A finite element (FE) model is designed for the labscaled tendon-anchorage. The FE model of the PZT-interface is tuned as its impedance signatures meet the experimental test results (presented by [13]) at the same frequency ranges and also with identical patterns. Equivalent model properties of the FE model corresponding to prestress forces inflicted on the lab-tested structure are identified from the fine-tuning practice.

\section{Theory of Impedance Monitoring}

2.1. Electromechanical Impedance. To monitor structural change, a piezoelectric material (e.g., PZT) is surface-bonded to structure at the examined region. As shown in Figure 2, the interaction between the PZT and the structure is simply explained by the $1 \mathrm{D}$ free-body diagram of PZT-structure system. Due to the inverse piezoelectric effect, an input harmonic voltage $V(\omega)$ induces a deformation of PZT. Because 


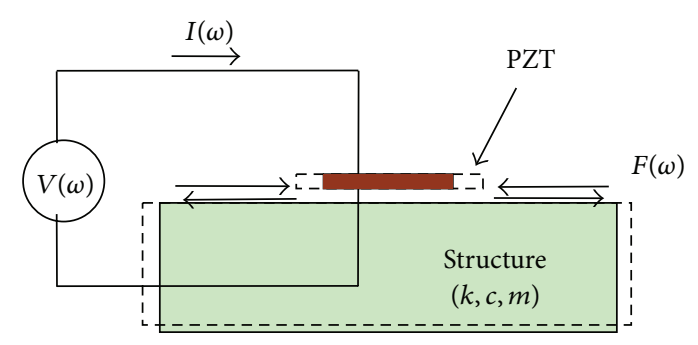

FIgURE 2: Model of coupling interaction between PZT transducer and structure.

the PZT is bonded to the structure, a force $F(\omega)$ against that deformation is induced into the structure and the PZT as well.

For 1-dof system, structural mechanical impedance of the host structure is obtained by the ratio of force $F(\omega)$ to velocity $\dot{u}(\omega)$ as follows [1]:

$$
Z_{s}(\omega)=\frac{F(\omega)}{\dot{u}(\omega)}=c+m \frac{\omega^{2}-\omega_{n}^{2}}{\omega} i,
$$

where $c$ and $m$ are the damping coefficient and the mass of the structure, respectively; $\omega_{n}$ is the angular natural frequency of the structure; and $\omega$ is the angular frequency of the excitation voltage. As shown in (1), structural mechanical impedance is a function of mass, damping, and stiffness (i.e., stiffness is introduced from natural frequency, $k=m \omega_{n}^{2}$ ). Thus, the change in structural parameters can be represented by the change in structural mechanical impedance.

In practice, the electric current $I(\omega)$ is measured and then it is utilized to calculate electromechanical impedance as follows [1]:

$$
Z(\omega)=\frac{V}{I}=\left\{i \omega \frac{w_{a} l_{a}}{t_{a}}\left[\widehat{\varepsilon}_{33}^{T}-\frac{1}{Z_{a}(\omega) / Z_{s}(\omega)+1} d_{3 x}^{2} \widehat{Y}_{x x}^{E}\right]\right\}^{-1},
$$

where $\hat{Y}_{x x}^{E}=(1+i \eta) Y_{x x}^{E}$ is the complex Young's modulus of the PZT patch at zero electric field; $\widehat{\varepsilon}_{x x}^{T}=(1-i \delta) \varepsilon_{x x}^{T}$ is the complex dielectric constant at zero stress; $d_{3 x}$ is the piezoelectric coupling constant in $x$-direction at zero stress; $k=\omega \sqrt{\rho / \widehat{Y}_{x x}^{E}}$ is the wave number where $\rho$ is the mass density of the PZT patch; and $w_{a}, l_{a}$, and $t_{a}$ are the width, length, and thickness of the piezoelectric transducer, respectively. The parameters $\eta$ and $\delta$ are structural damping loss factor and dielectric loss factor of piezoelectric material, respectively.

As shown in (2), the electromechanical impedance, $Z(\omega)$, is a combining function of the mechanical impedance of the host structure, $Z_{s}(\omega)$, and that of the piezoelectric patch, $Z_{a}(\omega)$. Therefore, the change in structural parameters $(k, m$, and $c$ ) can be represented by the change in electromechanical impedance.

An important issue for impedance monitoring is to decide the target frequency range. The frequency range should be selected appropriately in order to realize structural change in electromechanical impedance. Generally, if the excitation frequency is not identical to the natural frequency of the host structure (i.e., $\omega \neq \omega_{n}$ ), the impedance of the structure is very large compared with the mechanical impedance of the PZT sensor (i.e., $\left.Z_{s}(\omega) \gg Z_{a}(\omega)\right)$. As a result, the term $Z_{a}(\omega) / Z_{s}(\omega)$ is neglected in (2). On the other hand, if the PZT sensor is excited by a frequency matching with the natural frequency of the structure (i.e., $\omega=\omega_{n}$ ), structural mechanical impedance takes only the term of damping coefficient (i.e., $Z_{s}(\omega)=c$ ). Consequently, the structural impedance for that frequency is comparable with the mechanical impedance of the PZT, and electromechanical impedance is expressed as follows:

$$
Z(\omega)=\left\{i \omega \frac{w_{a} l_{a}}{t_{a}}\left[\varepsilon_{33}^{T}-\frac{1}{Z_{a} / c+1} d_{3 x}^{2} \widehat{Y}_{x x}^{E}\right]\right\}^{-1}
$$

In (3), the contribution of structural mechanical impedance to electromechanical impedance is the damping coefficient $c$, which causes resonant responses in electromechanical impedance signature. It means that electromechanical impedance at resonance represents not only modal damping, but also the natural frequency of the structure. Therefore, the structural change could be identified sensitively by the change in electromechanical impedance at the resonant frequency.

2.2. Quantification of Electromechanical Impedance. To quantify the change in electromechanical impedance, the root mean square deviation (RMSD) index is utilized. RMSD index is calculated as [18]

$$
\operatorname{RMSD}\left(Z, Z^{*}\right)=\sqrt{\frac{\sum_{i=1}^{N}\left[Z^{*}\left(\omega_{i}\right)-Z\left(\omega_{i}\right)\right]^{2}}{\sum_{i=1}^{N}\left[Z\left(\omega_{i}\right)\right]^{2}}},
$$

where $Z\left(\omega_{i}\right)$ and $Z^{*}\left(\omega_{i}\right)$ are the impedances measured at two events for the $i$ th frequency, respectively, and $N$ denotes the number of frequency points in the sweep. Ideally, the RMSD is equal to 0 if the two events are identical (e.g., there is no structural change). Otherwise, the RMSD is larger than 0.

The correlation coefficient deviation (CCD) index can also be used to quantify the change of the whole impedance signatures [3]. The CCD index is calculated as follows:

$$
\begin{aligned}
& \text { CCD } \\
& =1-\frac{1}{\sigma_{Z} \sigma_{Z}^{*}} E\left\{\left[\operatorname{Re}\left(Z_{i}\right)-\operatorname{Re}(\bar{Z})\right]\left[\operatorname{Re}\left(Z_{i}^{*}\right)-\operatorname{Re}\left(\bar{Z}^{*}\right)\right]\right\},
\end{aligned}
$$

in which $E[\cdot]$ is the expectation operation; $\operatorname{Re}\left(Z_{i}\right)$ signifies the real parts of the electromechanical impedances of the $i$ th frequency; $\operatorname{Re}(\bar{Z})$ signifies the mean values of impedance signatures (real part); and $\sigma_{Z}$ signifies the standard deviation values of impedance signatures. Note that the asterisk $(*)$ denotes the structural change. The CCD index is equal to 0 if there is no structural change. Otherwise, the CCD is larger than 0 . 


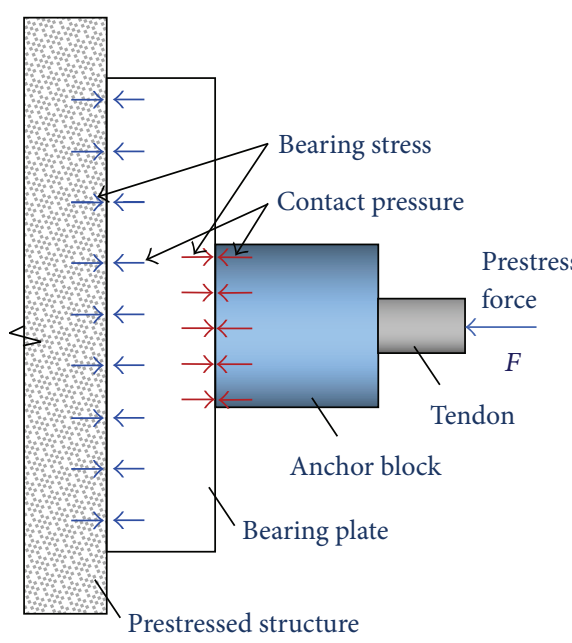

(a)

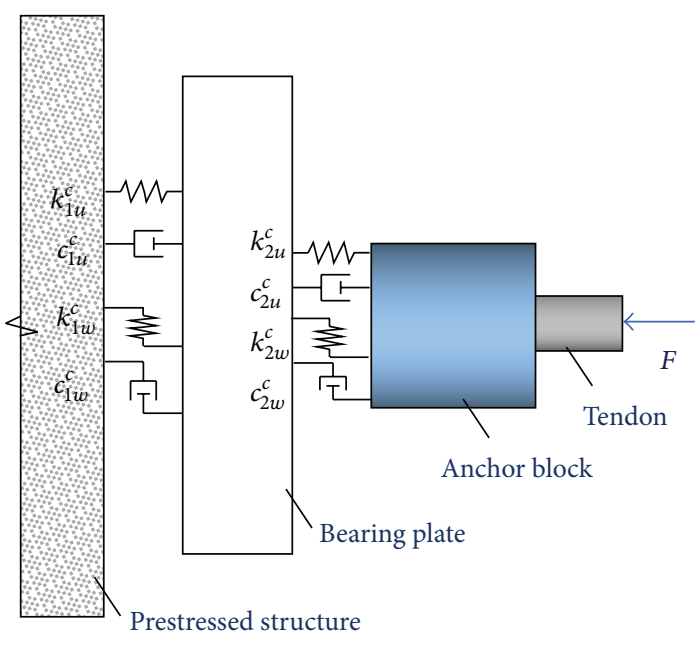

(b)

FIGURE 3: Structural model of tendon-anchorage: (a) force equilibrium and (b) analytical model.

\section{Mountable PZT-Interface for Tendon-Anchorage Connection}

3.1. Structural Model of Tendon-Anchorage. A tendon-anchorage subsystem can be modeled by a series of components such as bearing plate, anchor block, and tendon and contact forces in equilibrium condition, as shown in Figure 3(a). The prestress force is modeled by tendon force acting on the anchor block and transformed to contact pressure and bearing stress in the interface of anchor block and bearing plate. According to the contact mechanism [19], the interaction in the contact interface can be simplified by damping coefficients and spring stiffness parameters, as shown in Figure 3(b). On the other hand, the variation of interfacial stiffness and damping parameters are associated with the variation of contact pressures [20]. Hence, the variation of tendon force can be treated as the variation of those structural parameters at the contact interface.

\subsection{Structural Model of Tendon-Anchorage with Mountable} PZT-Interface. A fixed-type PZT-interface was proposed to overcome the difficulties in monitoring the high frequency response corresponding to the change in the tendon-anchorage system [12]. The interface is a thin plate equipped with a PZT patch. It reduces the frequency range enough to deal within $10-100 \mathrm{kHz}$ measurement. However, the fixed-type design of this interface has drawbacks since it interferes with the bearing capacity of the tendon-anchorage and also it needs to be installed during the construction.

As an alternative measuring technique, a mountable PZTinterface has been newly modeled in order to overcome the limitations of the fixed-type interface in practice, as shown in Figure 4(a). The mountable interface is a clamped-clamped beam with a PZT patch bonded on its middle. As tightly bonded to the surface of the bearing plate, the clamped interfacing makes the stress fields of the PZT-interface almost equivalent to those of the bearing plate on its surface, while the top and bottom midsurfaces are freely deformed along with the deformation in the bearing plate. Therefore, any change in structural parameters due to cable force-loss would lead to the change in the EM impedance response of PZTinterface (Figure 4(b)).

On the basis of the coupling interaction between the PZT sensor and the host structure $[1,17]$, a 1-dof structural model using a series of mass-spring-dampness is proposed as shown in Figure 4(c). The clamped-clamped PZT-interface is modeled as 1-dof system with its mass $\left(m^{i}\right)$, stiffness $\left(k^{i}\right)$, and damping parameters $\left(c^{i}\right)$, as shown in Figure 4(c). Also, the tendon-anchorage is modeled as bearing plate's mass $\left(m^{b}\right)$, bearing plate's stiffness $\left(k^{b}\right)$ and damping $\left(c^{b}\right)$, contact stiffness $\left(k_{1}^{c}, k_{2}^{c}\right)$, and contact damping $\left(c_{1}^{c}, c_{2}^{c}\right)$. The series model is selected for the simplification since the bearing plate is target structure and the contact parameters are considered as boundary conditions. The equivalent structural stiffness of the PZT-interface on the bearing plate $\left(k_{e}^{\text {interface }}\right)$ is simplified as follows:

$$
k_{e}^{\text {interface }}=\frac{\gamma k^{c} k^{i}}{\gamma k^{c}+k^{i}},
$$

where $k^{c}$ is the total contact stiffness $\left(k^{c}=k_{1}^{c}+k_{2}^{c}\right)$ and $\gamma$ is a factor representing the ratio of the bearing plate's stiffness to the total contact stiffness as

$$
\gamma=\frac{\alpha}{1+\alpha}, \quad \alpha=\frac{k^{b}}{k^{c}} .
$$

Suppose $\beta=k^{i} /\left(\gamma k^{c}\right)$ is the ratio of the PZT-interface's stiffness to the equivalent contact stiffness; the equivalent structural stiffness of the PZT-interface can be rewritten as

$$
k_{e}^{\text {interface }}=\left(\frac{\beta}{1+\beta}\right) \gamma k^{c} .
$$

For the simplified model of the tendon-anchorage without the mountable PZT-interface $\left(k^{i}=\beta=0\right)$, the bearing plate is 


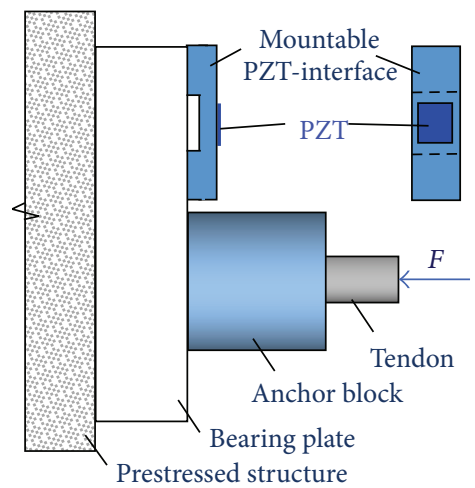

(a)

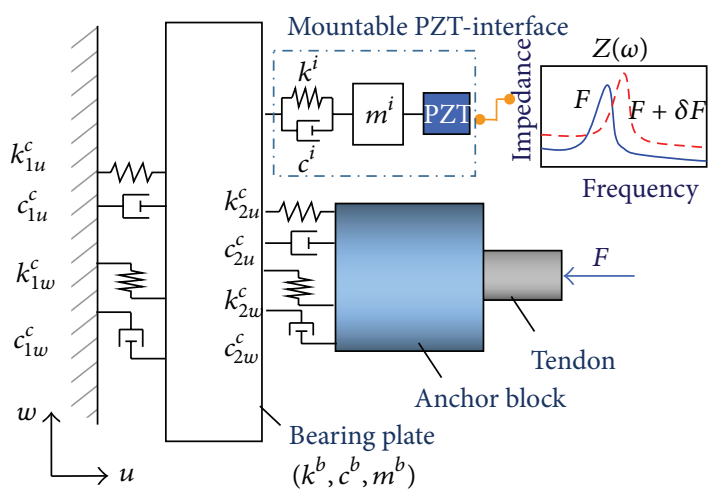

(b)

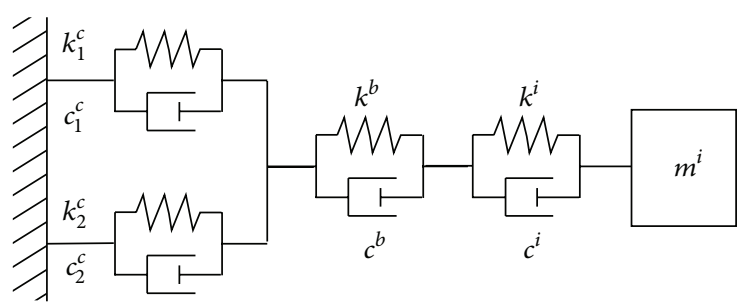

(c)

FIgURE 4: Structural model of tendon-anchorage with a mountable PZT-interface: (a) tendon-anchorage with PZT-interface; (b) analytical model; and (c) 1-dof model.

the target structure and its equivalent structural stiffness $k_{e}^{\text {bearing }}$ is derived on the basis of (8) as follows:

$$
k_{e}^{\text {bearing }}=\gamma k^{c} .
$$

Since the bearing plate is clamped between two surfaces, its equivalent stiffness would be very large due to the contact pressure and the stress field acting at the interface. Substituting (9) into (8) leads the ratio of the equivalent stiffness with the PZT-interface $\left(k_{e}^{\text {interface }}\right)$ to that of the bearing plate $\left(k_{e}^{\text {bearing }}\right)$ as follows:

$$
\frac{k_{e}^{\text {interface }}}{k_{e}^{\text {bearing }}}=\frac{\beta}{1+\beta} .
$$

As the stiffness of the PZT-interface is much smaller than the contact stiffness (i.e., $\beta \ll 1$ ), (10) is simplified as $k_{e}^{\text {interface }} / k_{e}^{\text {bearing }} \approx \beta$ and it leads $k_{e}^{\text {interface }} \ll k_{e}^{\text {bearing }}$. Assume the mass of the PZT-interface is comparable with that of the bearing plate, natural frequencies of the PZT-interface subsystem would be quite reduced as compared to those of the tendon-anchorage model.

For simplified structural models, structural parameters are needed to be determined to obtain the consistent experimental results. The structural parameters could be identified from the fine-tuning process by matching the calculated resonant response of the simplified model and the measured resonant response of the experimental model $[20,21]$. In the present study, the 1-dof structural model of the PZTinterface was proposed firstly to explain how to represent the loss of cable force from the change in the electromechanical impedance (Figure 4(c)) and secondly to prove that the sensitive frequency band could be reduced when the PZT-interface device is implemented into tendon-anchorage (see (10)).

\section{Numerical Verification of Mountable PZT-Interface for Cable Force Monitoring}

4.1. FE Modeling for Numerical Simulation of Tendon-Anchorage. In order to numerically evaluate the applicability of the PZT-interface device for cable force monitoring using impedance-based technique, FE model of tendon-anchorage connection was established by the commercially available FE package, COMSOL Multiphysics [22]. Figure 5 shows the geometry of the FE model that was in accordance with the lab-scale model test presented by Huynh and Kim [13]. It should be noted that the bonding layers between the PZT sensor and PZT-interface with the mother structure were not simulated in the present work. In FE modeling, the bearing plate, anchor head, and the PZT-interface were discretized by the elastic solid elements in 3D, as shown in Figure 6(a). The properties of the steel anchorage and the aluminum interface specified in the FE model are listed in Table 1. The PZT patch is added by the piezoelectric material, PZT-5A type as shown in Table 2, which could deal with both mechanical and electrical fields. To acquire the electromechanical impedance, a harmonic excitation voltage with an amplitude of $1 \mathrm{~V}$ was simulated to the top surface of the PZT patch, and the bottom one was set as the ground electrode. 


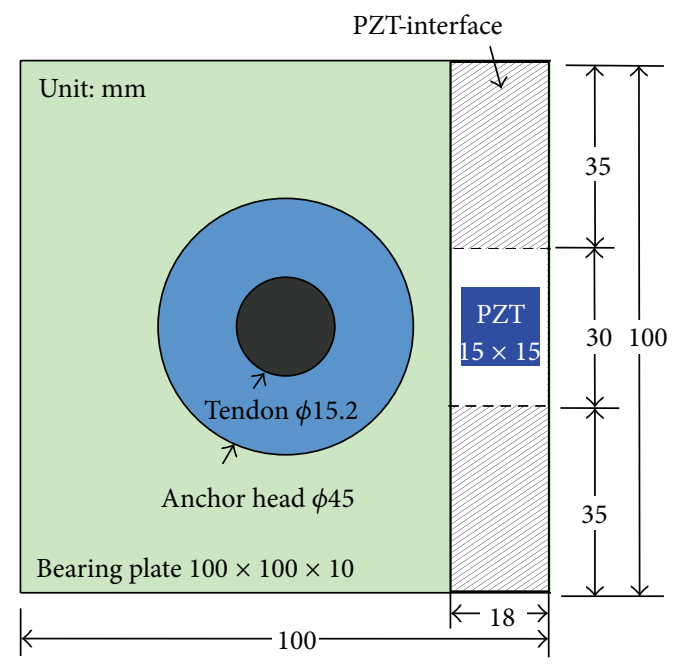

Front view

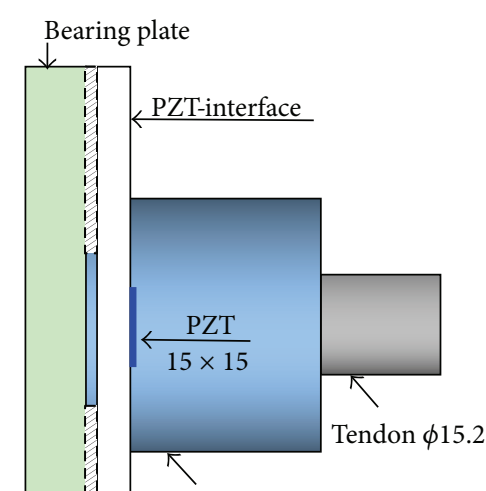

Anchor head $\phi 45$

Side view

FIGURE 5: Geometry of lab-scaled tendon-anchorage equipped with PZT-interface [13].

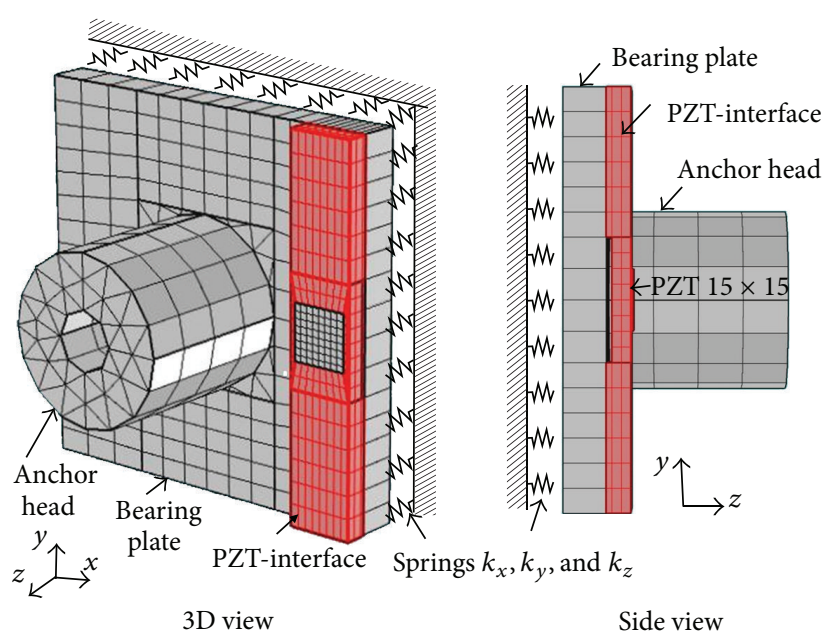

(a)

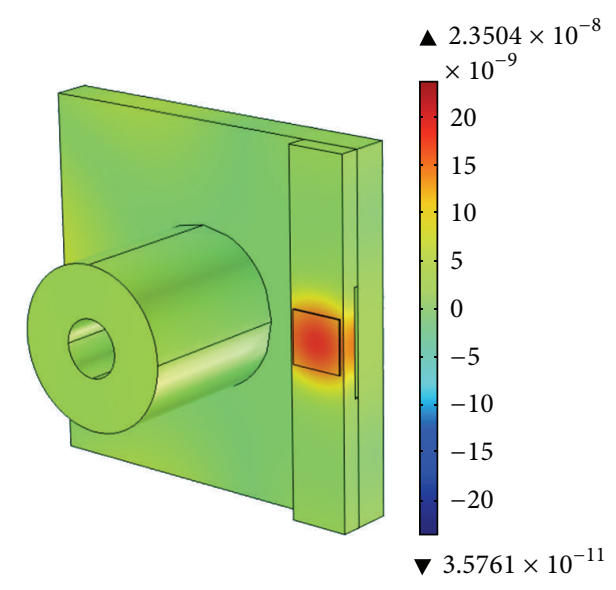

(b)

FIGURE 6: FE model of tendon-anchorage subsystem: (a) meshing and boundary condition and (b) deformation excited by PZT sensor at $19.52 \mathrm{kHz}$.

TABLE 1: Material properties of cable-anchorage connection.

\begin{tabular}{lcc}
\hline Parameters & PZT-interface & $\begin{array}{c}\text { Bearing plate and } \\
\text { anchor head }\end{array}$ \\
\hline Young's modulus, $E(\mathrm{GPa})$ & 70 & 200 \\
Poisson's ratio, $v$ & 0.33 & 0.3 \\
Mass density, $\rho\left(\mathrm{kg} / \mathrm{m}^{3}\right)$ & 2700 & 7850 \\
Damping loss factor, $\eta$ & 0.001 & 0.02 \\
\hline
\end{tabular}

According to the foregoing analytical model of tendonanchorage connection, the variation of tendon force can be treated as the variation of structural parameters at the contact interface. Therefore, the cable force can be monitored via the interfacial structural stiffness (so-called contact stiffness). As shown in Figure 6(a), spring elements in the $x$-, $y$-, and $z$-axes were added to the contact surface of the bearing plate to represent the contact stiffness caused by cable force. It is assumed that the structural parameters are uniformly distributed on the contact boundary surface. As given in Table 3, four cases of spring stiffness (i.e., C0, C1, C2, and C3) were considered to investigate the change in the piezoelectric impedance response of PZT-interface. By assuming that the variation of cable force mainly causes the variation of spring constant in the direction normal to the contacting surface, only the variation of $k_{z}$ is simulated in the $\mathrm{FE}$ analysis.

As shown in Figure 7, the real part of the electromechanical impedance computed by the numerical simulation (case $\mathrm{C} 0$ in Table 3 ) is compared to the corresponding experimental 
TAble 2: Properties of PZT-5A patch [23].

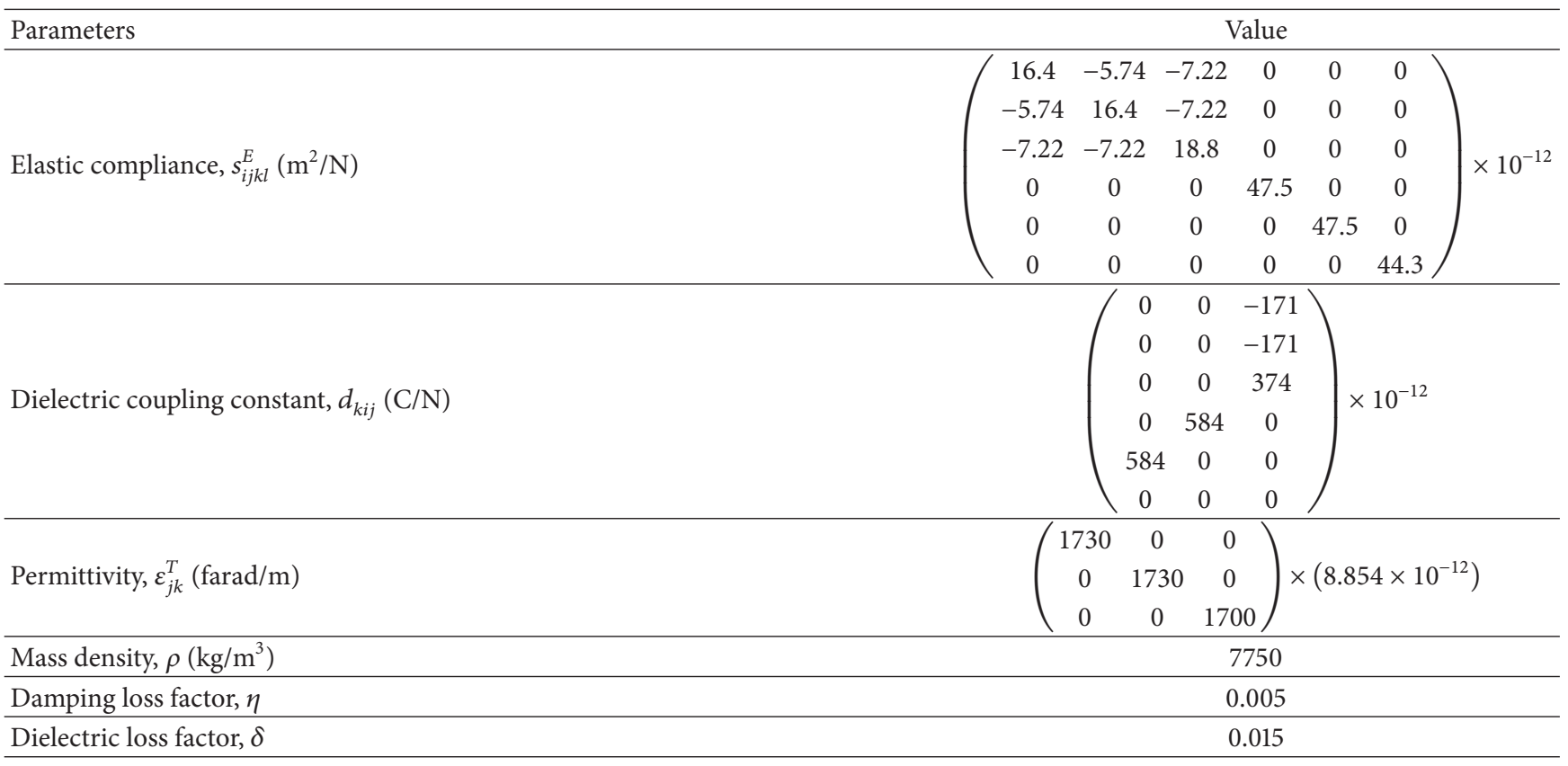

TABLE 3: Interfacial stiffness versus resonant frequency.

\begin{tabular}{lcccccc}
\hline \multirow{2}{*}{ Scenarios } & \multicolumn{3}{c}{ Interfacial stiffness $\left(\mathrm{N} / \mathrm{m} / \mathrm{m}^{2}\right)$} & \multicolumn{3}{c}{ Resonant frequency $(\mathrm{kHz})$} \\
& $k_{x}=k_{y}$ & $k_{z}$ & $\Delta k_{z}(\%)$ & $f_{1}$ & $\Delta f_{1}(\%)$ & $f_{1}$ \\
\hline C0 & $15 \times 10^{11}$ & $40 \times 10^{11}$ & 0 & 19.68 & 0 & 82.68 \\
C1 & $15 \times 10^{11}$ & $35 \times 10^{11}$ & -12.5 & 19.64 & -0.20 & 82.60 \\
C2 & $15 \times 10^{11}$ & $30 \times 10^{11}$ & -25 & 19.56 & -0.61 & 82.56 \\
C3 & $15 \times 10^{11}$ & $25 \times 10^{11}$ & -37.5 & 19.52 & -0.81 & -0.10 \\
\hline
\end{tabular}

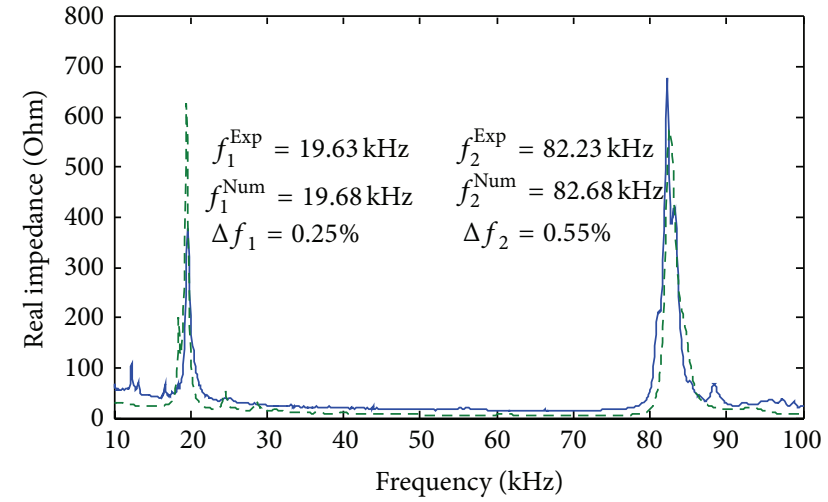

$\begin{array}{ll}\text { - } & \text { Exp. } T_{0}=49.05 \mathrm{kN} \\ -- & \text { Number C0 } k_{z}=40 \times 10^{11} \mathrm{~N} / \mathrm{m} / \mathrm{m}^{2}\end{array}$

FIGURE 7: Numerical versus experimental impedance signatures.

result (for tension force $49.05 \mathrm{kN}$ ). It is worth noting that the spring constants specified in the C0 scenario were obtained by using trial-and-error method, and the identification of the contact stiffness is beyond the scope of this paper. As observed in Figure 7, the resonance occurred within
$10 \mathrm{kHz} \sim 100 \mathrm{kHz}$, and both resonant and nonresonant regions of the numerical impedance signatures show good agreement with those of the experimental result [13].

The difference in the resonant frequencies between the FE modeling and the lab-scaled testing is very small, about $0.25 \%$ and $0.55 \%$ for the first and the second resonant vibrations, respectively. It indicates that the FE simulation can provide reasonable impedance responses for cable force monitoring via interfacial stiffness monitoring. As shown in Figure 6(b), the deformation contour of the anchorage excited by PZT patch was generated at the resonant frequency of $19.52 \mathrm{kHz}$. It is also observed that the maximum displacement of the PZTinterface is about $2.35 \times 10^{-8} \mathrm{~m}$ due to the resonance event.

4.2. Contact Stiffness versus Impedance Response. Figure 8 shows real impedance signatures of the PZT-interface obtained by the FE modeling in the wide frequency range $10 \mathrm{kHz}-100 \mathrm{kHz}$ and two sensitive frequency ranges of 15$25 \mathrm{kHz}$ and $75-95 \mathrm{kHz}$ for four contact stiffness scenarios (as listed in Table 3). Similar to the experiment, the impedance signatures were recorded with 901 interval points for the frequency band of $10-100 \mathrm{kHz}$ and 501 points for both frequency bands of $15-25 \mathrm{kHz}$ and $75-95 \mathrm{kHz}$. As observed in Figures $8(\mathrm{~b})$ and $8(\mathrm{c})$, the impedance signatures in 


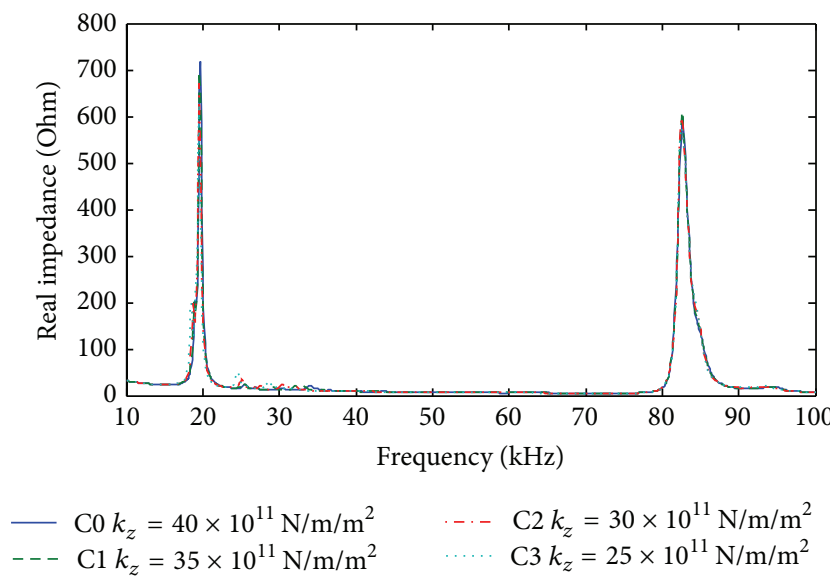

(a) Frequency range $10-100 \mathrm{kHz}$

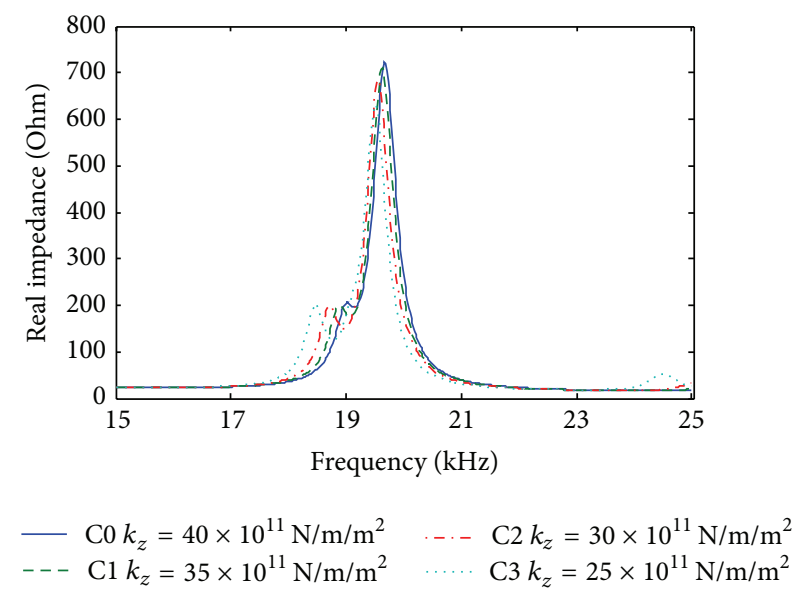

(b) Frequency range $15-25 \mathrm{kHz}$

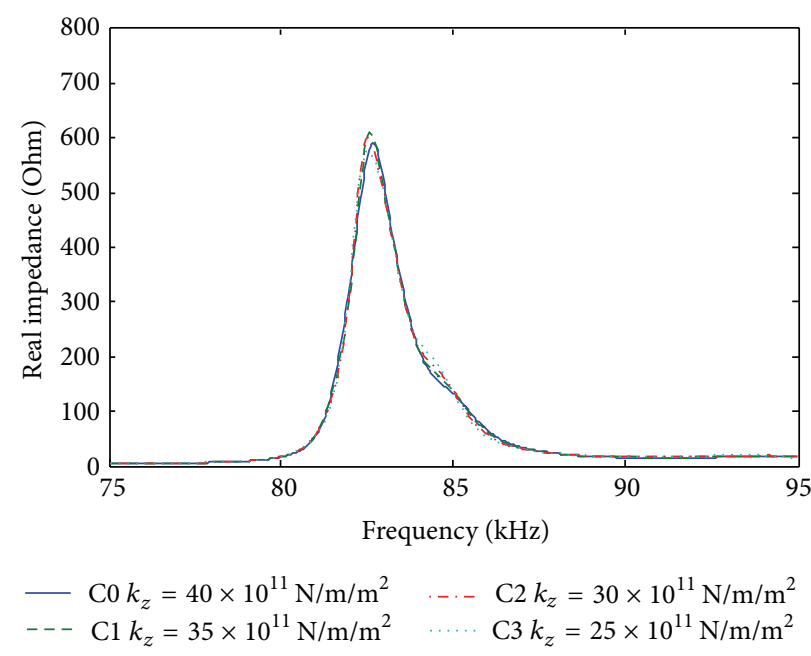

(c) Frequency range $75-95 \mathrm{kHz}$

Figure 8: Impedance signatures of PZT-interface under various contact stiffness.

the resonant bands of $15-25 \mathrm{kHz}$ and $75-95 \mathrm{kHz}$ are varied when decreasing the contact stiffness $k_{z}$. The frequency range of $15-25 \mathrm{kHz}$ is more sensitive than that of $75-95 \mathrm{kHz}$. The resonant frequencies tend to decrease when decreasing the spring stiffness $k_{z}$. The change in the resonant frequency due to the contact stiffness-loss is summarized in Table 3. The frequency-shift is very small, $0.81 \%$ and $0.19 \%$ for the first and the second resonant frequencies, respectively. Obviously, the pattern of the numerical impedance variation due to the change in contact stiffness is well-matched with the experimental observations [13]. Furthermore, the impedance response via the PZT-interface was sensitive to the change in contact stiffness even when the examined frequency range was $10 \mathrm{kHz} 100 \mathrm{kHz}$.

For contact stiffness monitoring, both RMSD values (see (4)) and CCD indices (see (5)) are examined. Figures 9 and 10, respectively, show the change in RMSD and CCD indices associated with the decrement of contact stiffness for the wide frequency band (i.e., $10-100 \mathrm{kHz}$ ) and the narrow ones (i.e., $15-25 \mathrm{kHz}$ and $75-95 \mathrm{kHz}$ ). As observed in the figures, RMSD and CCD indices increase linearly with the loss of interfacial stiffness. It is also observed that RMSD and CCD indices of the wide frequency range $10-100 \mathrm{kHz}$ show a good indication of the contact stiffness-loss as the sensitive frequency range $15-25 \mathrm{kHz}$. In comparison, of RMSD and CCD approaches, RMSD indices are varied much higher than the CCD indices due to the contact stiffness variation for all considered frequency ranges (i.e., $10-100 \mathrm{kHz}, 15-25 \mathrm{kHz}$, and $75-95 \mathrm{kHz}$ ). These numerical results are consistent with the experimental results obtained from the lab-scaled test structure described previously. From the feature analysis of the impedance signatures, the RMSD is found to be the sensitive indication of the contact stiffness-loss as the prestress force was reduced.

\section{Summary and Conclusions}

In this study, the feasibility of the mountable PZT-interface was numerically analyzed for impedance monitoring in the tendon-anchorage connection. Firstly, electromechanical 


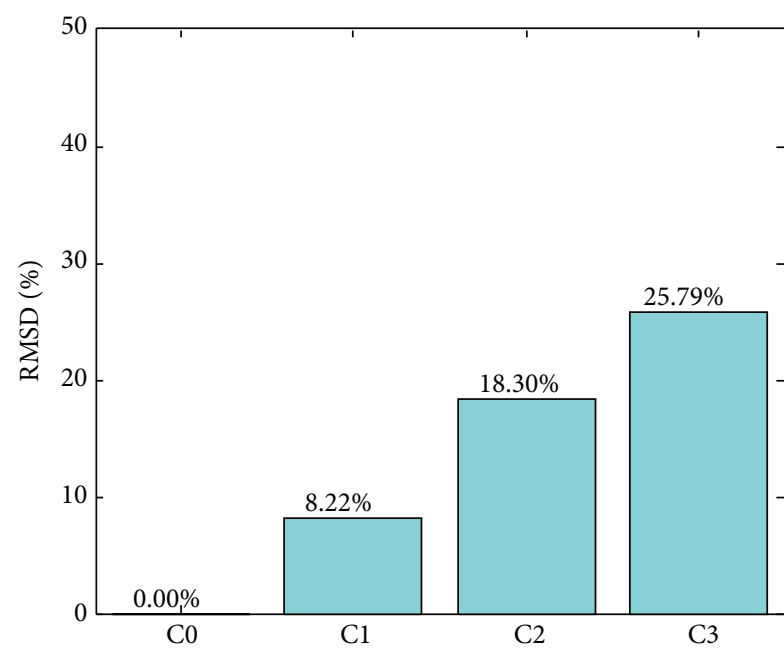

(a) Frequency range $10-100 \mathrm{kHz}$

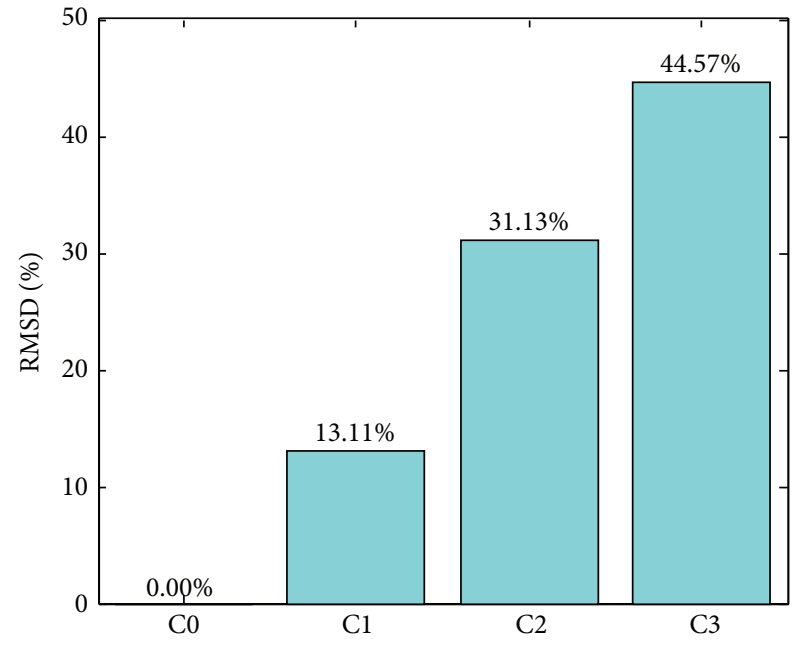

(b) Frequency range $15-25 \mathrm{kHz}$

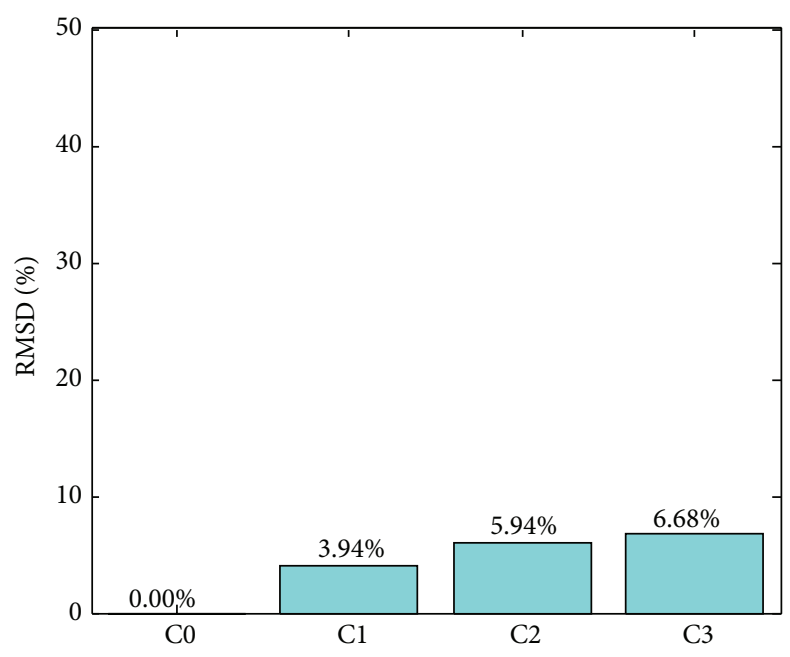

(c) Frequency range $75-95 \mathrm{kHz}$

FIgURE 9: Contact stiffness monitoring by RMSD index.

impedance monitoring and feature classification methods were outlined. Secondly, a structural model of tendonanchorage subsystem with mountable PZT-interface was designed for impedance monitoring. Finally, the feasibility of the mountable PZT-interface was numerically examined. A finite element (FE) model was designed for the lab-scaled tendon-anchorage. The FE model of the PZT-interface was tuned as its impedance signatures met the experimental test results presented by Huynh and Kim [13]. Equivalent model properties of the FE model corresponding to prestress forces inflicted on the lab-tested structure were identified from the fine-tuning practice.

The interfacial stiffness which represents the prestress force in the tendon-anchorage subsystem was successfully monitored by the electromechanical impedance response of the PZT-interface. The feature analysis of the impedance signatures shows that the RMSD changed to make the sensitive indication of the contact stiffness-loss as the prestress force was reduced. The impedance response via the PZTinterface was sensitive to the change in contact stiffness even when the examined frequency range was $10 \mathrm{kHz} 100 \mathrm{kHz}$. It is noted that two resonance frequencies occurred near $20 \mathrm{kHz}$ and $82 \mathrm{kHz}$ by implementing the mountable interface device. Since the PZT-interface is mobile and adaptable to be applied in any existing cable-anchorage connections, this numerical evaluation is promising for designing appropriate devices for practical applications. As for the future work, the bonding layer should be considered in the numerical simulation to examine its effect on the electromechanical impedance of the PZT-interface.

\section{Conflict of Interests}

The authors declare that there is no conflict of interests regarding the publication of this paper. 


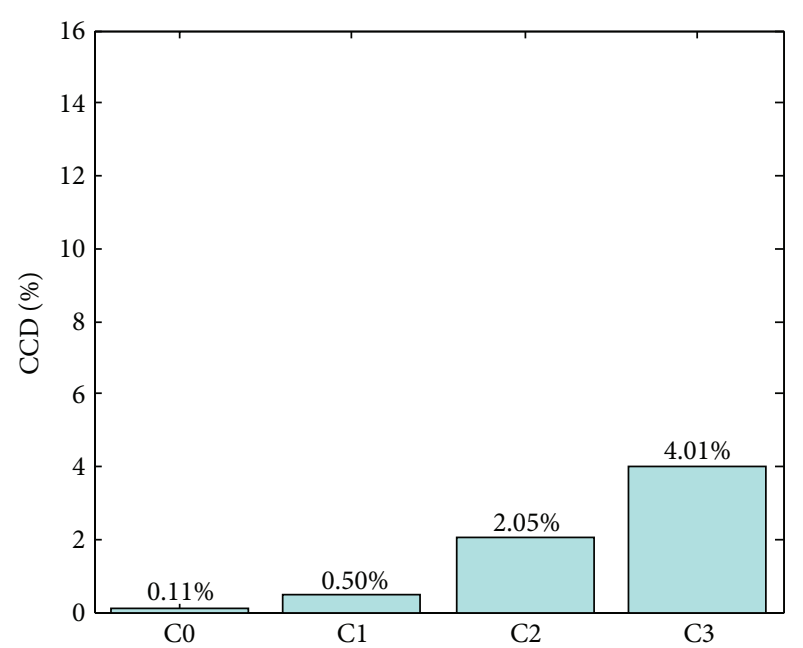

(a) Frequency range $10-100 \mathrm{kHz}$

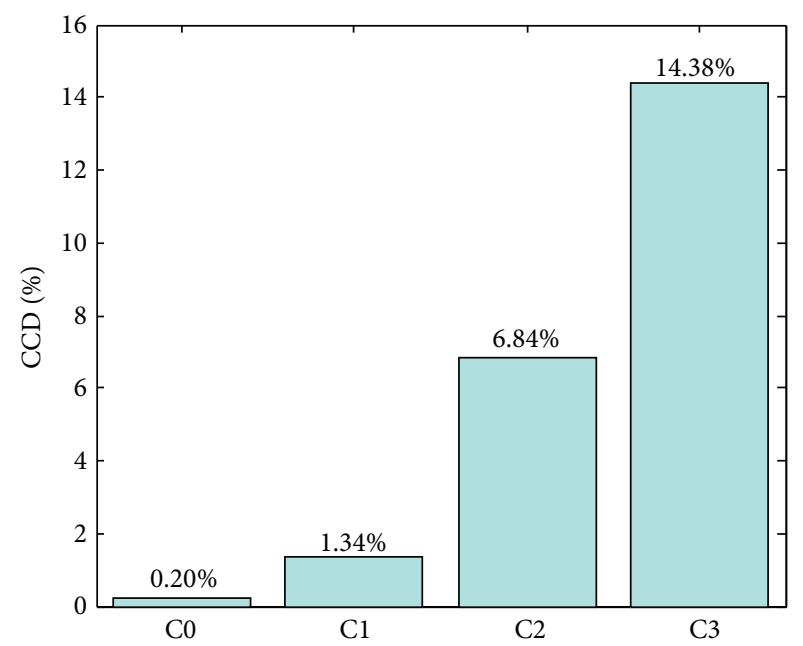

(b) Frequency range $15-25 \mathrm{kHz}$

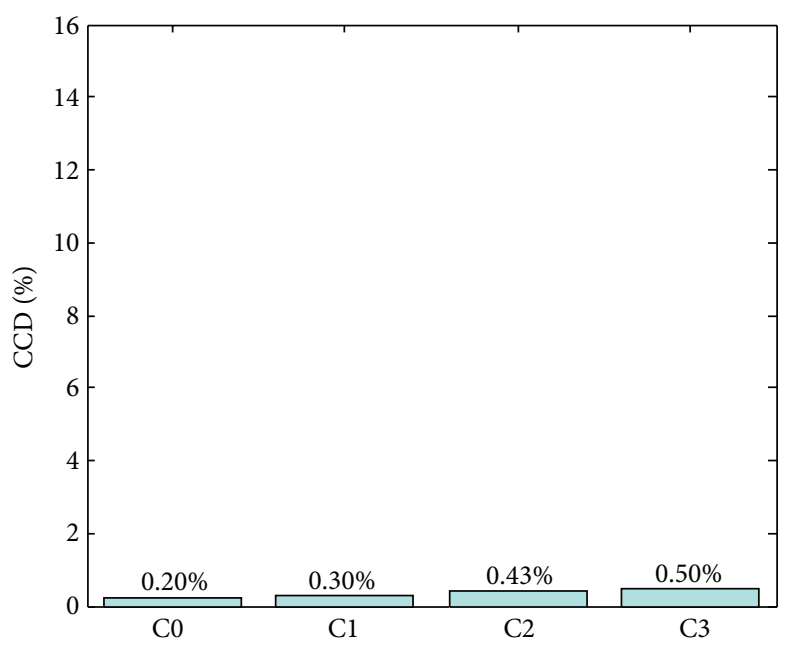

(c) Frequency range $75-95 \mathrm{kHz}$

Figure 10: Contact stiffness monitoring by CCD index.

\section{Acknowledgments}

This research was supported by a grant from a Strategic Research Project (Development of Smart Prestressing and Monitoring Technologies for Prestressed Concrete Bridges) funded by the Korea Institute of Construction Technology. The graduate student, Mr. Thanh-Canh Huynh, involved in this research was also partially supported by the Brain Korea 21 Plus (BK21 Plus) Program of Korean Government.

\section{References}

[1] C. Liang, F. P. Sun, and C. A. Rogers, "Coupled electromechanical analysis of adaptive material systems-determination of the actuator power consumption and system energy transfer," Journal of Intelligent Material Systems and Structures, vol. 5, no. 1, pp. 12-20, 1994.

[2] G. Park, H. H. Cudney, and D. J. Inman, "Feasibility of using impedance-based damage assessment for pipeline structures,"
Earthquake Engineering and Structural Dynamics, vol. 30, no. 10, pp. 1463-1474, 2001.

[3] A. N. Zagrai and V. Giurgiutiu, "Electro-mechanical impedance method for crack detection in thin plates," Journal of Intelligent Material Systems and Structures, vol. 12, no. 10, pp. 709-718, 2001.

[4] S. Bhalla and C. K. Soh, "Structural impedance based damage diagnosis by piezo-transducers," Earthquake Engineering \& Structural Dynamics, vol. 32, no. 12, pp. 1897-1916, 2003.

[5] Y. Yang, Y. Hu, and Y. Lu, "Sensitivity of PZT impedance sensors for damage detection of concrete structures," Sensors, vol. 8, no. 1, pp. 327-346, 2008.

[6] J.-T. Kim, W.-B. Na, J.-H. Park, and D.-S. Hong, "Hybrid health monitoring of structural joints using modal parameters and EMI signatures," in Smart Structures and Materials 2006-Sensors and Smart Structures Technologies for Civil, Mechanical, and Aerospace Systems, vol. 6174 of Proceedings of the SPIE, San Diego, Calif, USA, March 2006. 
[7] D. L. Mascarenas, Development of an impedance-based wirelesssensor node for monitoring of bolted joint preload [M.S. thesis], Department of Structural Engineering, University of California, San Diego, Calif, USA, 2006.

[8] J. T. Kim, J. H. Park, D. S. Hong, H. M. Cho, W. B. Na, and J. H. Yi, "Vibration and impedance monitoring for prestress-loss prediction in PSC girder bridges," Smart Structures and Systems, vol. 5, no. 1, pp. 81-94, 2009.

[9] J.-T. Kim, J.-H. Park, D.-S. Hong, and W.-S. Park, "Hybrid health monitoring of prestressed concrete girder bridges by sequential vibration-impedance approaches," Engineering Structures, vol. 32, no. 1, pp. 115-128, 2010.

[10] D. L. Mascarenas, M. D. Todd, G. Park, and C. R. Farrar, "Development of an impedance-based wireless sensor node for structural health monitoring," Smart Materials and Structures, vol. 16, no. 6, pp. 2137-2145, 2007.

[11] J.-H. Park, J.-T. Kim, D.-S. Hong, D. Mascarenas, and J. Peter Lynch, "Autonomous smart sensor nodes for global and local damage detection of prestressed concrete bridges based on accelerations and impedance measurements," Smart Structures and Systems, vol. 6, no. 5-6, pp. 711-730, 2010.

[12] K.-D. Nguyen and J.-T. Kim, "Smart PZT-interface for wireless impedance-based prestress-loss monitoring in tendonanchorage connection," Smart Structures and Systems, vol. 9, no. 6, pp. 489-504, 2012.

[13] T.-C. Huynh and J.-T. Kim, "Impedance-based cable force monitoring in tendon-anchorage using portable PZT-interface technique," Mathematical Problems in Engineering, vol. 2014, Article ID 784731, 11 pages, 2014.

[14] S.-W. Zhou, C. Liang, and C. A. Rogers, "An impedance-based system modeling approach for induced strain actuator-driven structures," Journal of Vibration and Acoustics, vol. 118, no. 3, pp. 323-331, 1996.

[15] S. Bhalla and C. K. Soh, "Structural health monitoring by piezoimpedance transducers. I: modeling," Journal of Aerospace Engineering, vol. 17, no. 4, pp. 154-165, 2004.

[16] C. Zuo, X. Feng, and J. Zhou, "A three-dimensional model of the effective electromechanical impedance for an embedded PZT transducer," Mathematical Problems in Engineering, vol. 2013, Article ID 218026, 10 pages, 2013.

[17] V. Giurgiutiu and A. N. Zagrai, "Embedded self-sensing piezoelectric active sensors for on-line structural identification," Journal of Vibration and Acoustics, vol. 124, no. 1, pp. 116-125, 2002.

[18] F. P. Sun, Z. Chaudhry, C. Liang, and C. A. Rogers, "Truss structure integrity identification using PZT sensor-actuator," Journal of Intelligent Material Systems and Structures, vol. 6, no. 1, pp. 134-139, 1995.

[19] K. L. Johnson, Contact Mechanics, Cambridge University Press, Cambridge, UK, 1985.

[20] S. Ritdumrongkul, M. Abe, Y. Fujino, and T. Miyashita, "Quantitative health monitoring of bolted joints using a piezoceramic actuator-sensor," Smart Materials and Structures, vol. 13, no. 1, pp. 20-29, 2004.

[21] V. Giurgiutiu and C. A. Rogers, "Modal expansion modeling of the electro-mechanical (E/M) impedance response of 1-D structures," in Proceedings of the European COST F3 Conference on System Identification \& Structural Health Monitoring, Universidad Politecnica de Madrid, Madrid, Spain, June 2000.

[22] COMSOL, Inc., 2013, /http://www.comsol.com.

[23] Efunda Inc., 2010, http://www.efunda.com. 

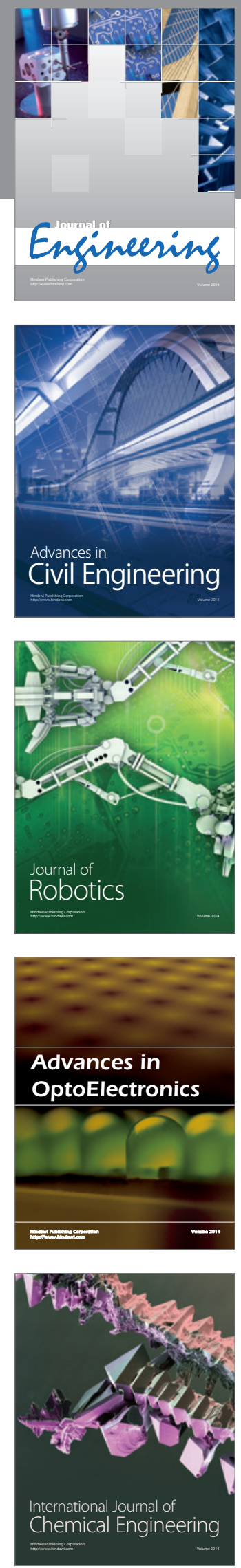

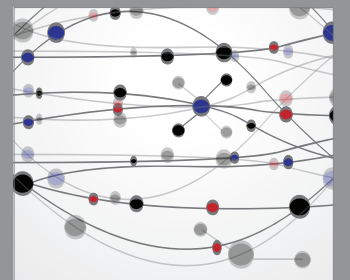

The Scientific World Journal
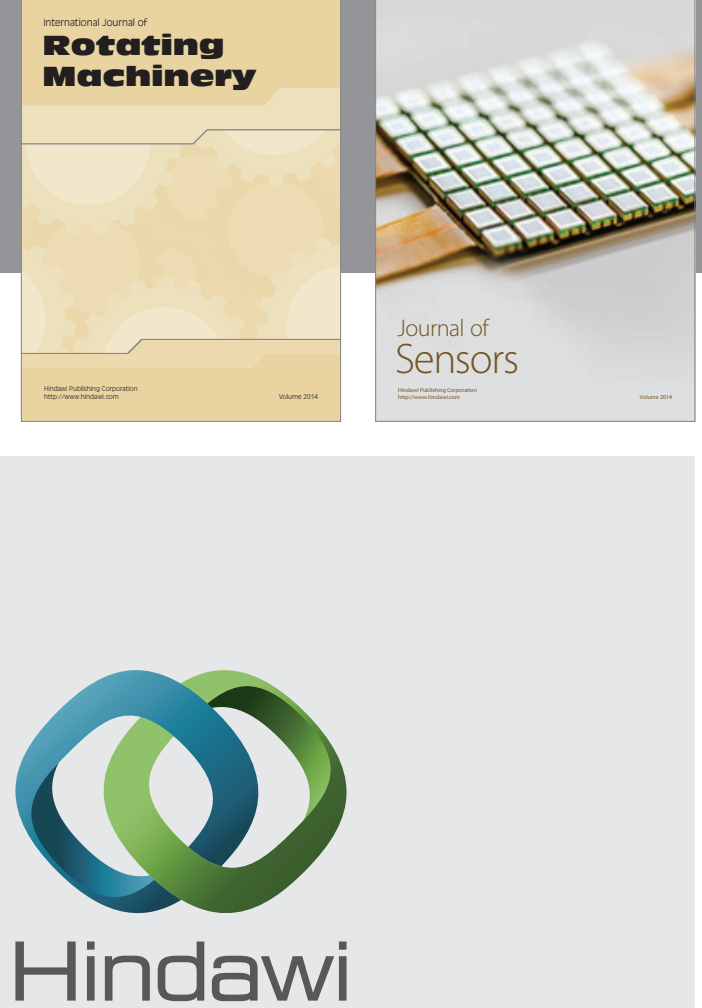

Submit your manuscripts at http://www.hindawi.com
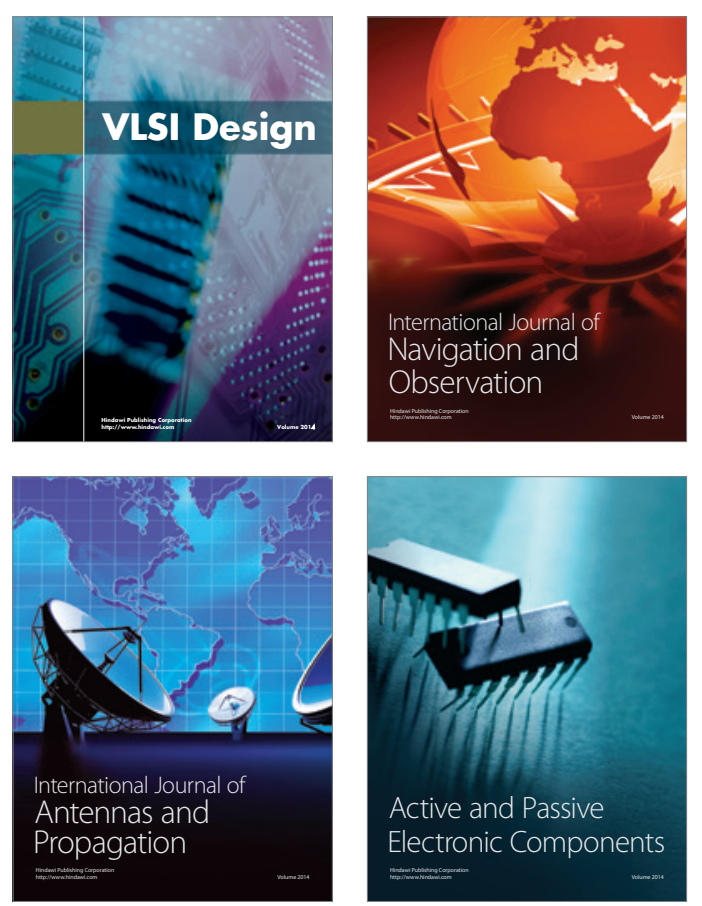
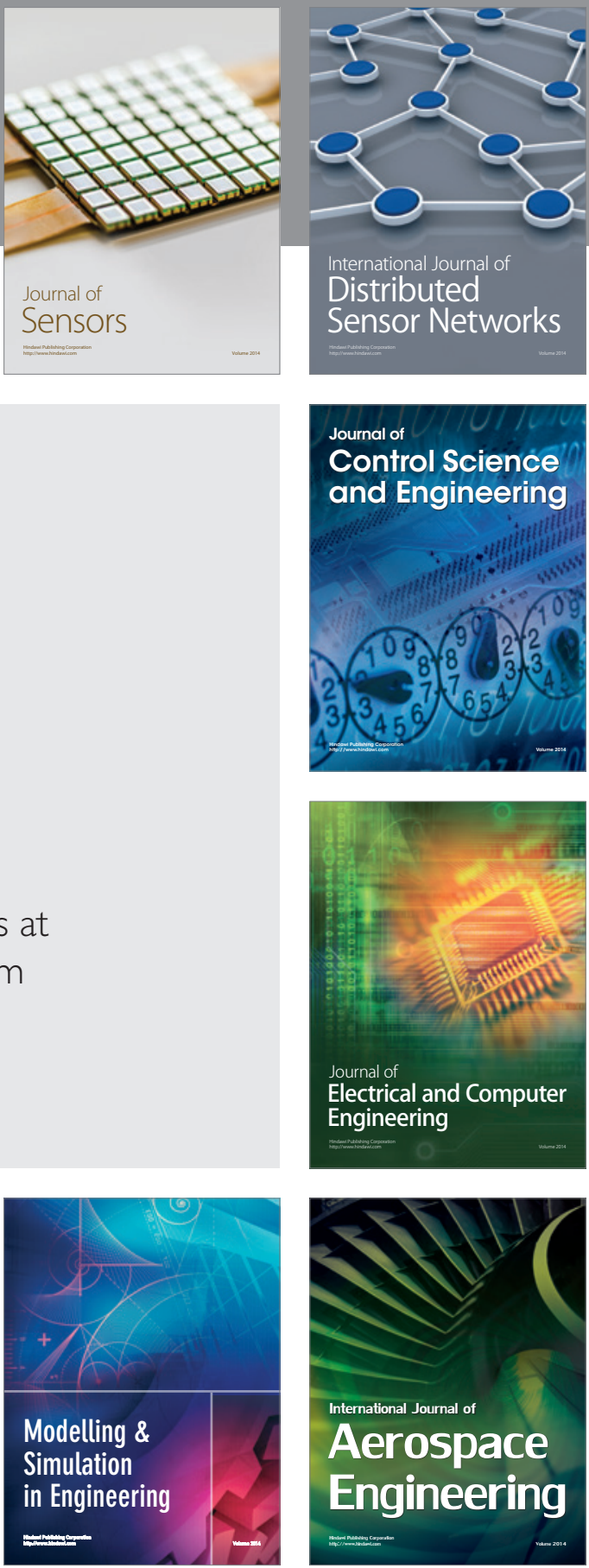

Journal of

Control Science

and Engineering
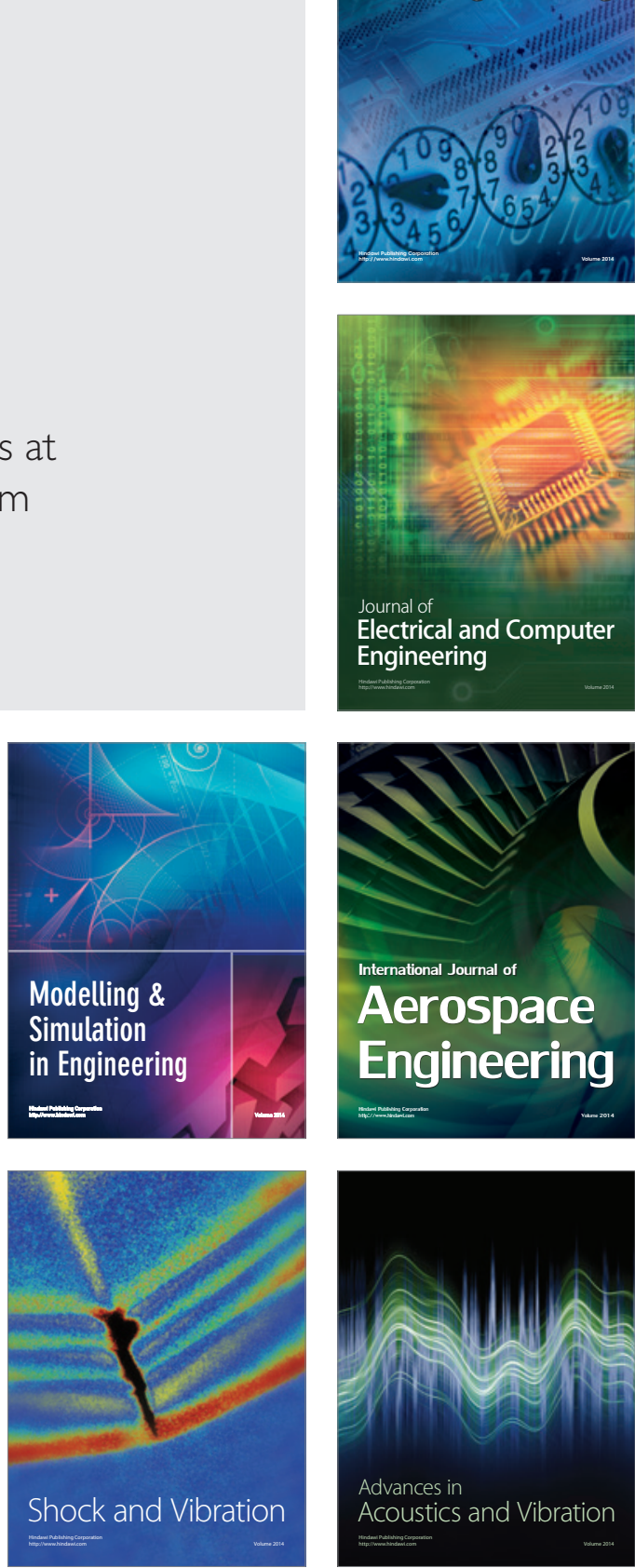